\title{
COMPREENDENDO A PESCA ARTESANAL SOB A ÓTICA DA MULTIFUNCIONALIDADE E PLURIATIVIDADE. ESTUDO DE CASO ${ }^{1}$
}

\author{
Diana Mendes Cajado ${ }^{2}$ \\ Ivana Leila Carvalho Fernandes ${ }^{3}$ \\ José Glaudervane Silva ${ }^{4}$ \\ Gema Galgani Silveira Leite Esmeraldo ${ }^{5}$
}

\section{Resumo}

As pesquisas relacionadas com multifuncionalidade e pluriatividade trazem como unidade de observação apenas as famílias que praticam agricultura familiar. Nesta pesquisa pretendeu-se ampliar estes olhares também para analisar as famílias que realizam a pesca artesanal, não só de forma isolada, mas combinada com a agricultura familiar e trabalhos não agrícolas. Deste modo o presente artigo apresenta como objetivos analisar a pesca artesanal desenvolvida na comunidade Apiques, Assentamento Maceió, Itapipoca-CE à luz da multifuncionalidade e identificar as atividades no âmbito da pluriatividade realizadas pelas famílias da comunidade pesquisada. Foi utilizada a metodologia Análise Diagnóstico de

\footnotetext{
${ }^{1}$ Este trabalho foi financiado pelo Ministério de Educação e Cultura (MEC)- Observatório de Educação do Campo, através da concessão de bolsa de mestrado em Economia Rural pela Universidade Federal do Ceará.

${ }_{2}$ Graduada em Engenheira de pesca (UFC). Mestre em Economia Rural (UFC). Doutoranda em Desenvolvimento e Meio Ambiente (UFC). Professora de Economia do Institudo Dom José de Educação e Cultura. Pesquisadora do Programa Risidência Agrária (UFC).E-mail: diana_cajado_pesca@hotmail.com

Graduada em Economia Doméstica (UFC). Graduada em Pedagogia (UVA). Especialista em Agricultura Familiar Camponesa e Educação do Campo (UFC). Mestre em Avaliação de Políticas Públicas (UFC). Pesquisadora do Programa Rsidência Agrária (UFC).E-mail: ivanaleila@yahoo.com.br

4 Graduado em Agronomia (UFC). Mestre em Economia Rural (UFC). E-mail: glaudervaneche@hotmail.com

${ }_{5}$ Graduada em Economia Doméstica (UFC). Mestre em Educação (UFPB). Doutora em Sociologia (UFC). Professora associada do Departamento de Economia Doméstica (UFC). Professora do Mestrado em Desenvolvimento e Meio Ambiente e do Mestrado em Avaliação de Polítcas Públicas (UFC). Coordenadora geral do Programa Residência Agrária (UFC). E-mail: gema@ufc.br
} 
Sistemas Agrários (ADSA) e a técnica de pesquisa observação participante. Os resultados foram: a construção da Tipologia dos Sistemas de Produção identificados, os Fluxogramas de Fertilidade e Produtos e os Calendários de atividades de dois tipos de sistemas de produção. Assim tem-se que a multifuncionalidade permite analisar a pesca artesanal sob aspectos que superam a lógica produtivista, enquanto modo de vida, por centralizar a família e suas relações com o espaço rural e a natureza, reconhecendo sua relevância para a sociedade através dos diversos serviços materiais e simbólicos prestados, além de evidenciar a importância de se ampliar as oportunidades de emprego no âmbito da pluriatividade.

Palavras-chave: Assentamentos Rurais. Pesca Artesanal. Multifuncionalidade. Pluriatividade. Análise Diagnóstico de Sistemas Agrários.

\title{
IN ADDITION SEA: ANALYSIS OF ARTISANAL FISHERY FROM THE PERSPECTIVE OF MULTIFUNCTIONALITY AND PLURIACTIVITY. CASE STUDY
}

\begin{abstract}
In this study, it was intended to expand these views to analyze families that realize or artisanal fishery, not only in isolation, but also combined to family farming and non agricultural activities. Therefore this paper aims to analyze artisanal fishery practiced in Apiques community, Settlement Maceió, Itapipoca-CE on the multifunctionality and pluriactivity view accessing the families income. Diagnostic Analyses of Agricultural Systems (DAAS) was the methodology used in a participant observation. As results, were elaborated the typology of the production systems identified, flowcharts of fertility and products and the activity calendar of two kind of production systems. Thus, it can be conclude that artisanal fishery, in the context of pluralities in rural areas, should be analysed from the admission of their several functions performed to society, expanding the multifunctionality view.
\end{abstract}

Key Words: Rural Settlement. Artisanal Fishery. Multifunctionality. Pluriactivity. Diagnostic Analyses of Agricultural Systems. 


\section{INTRODUÇÃO}

A pesca é uma das atividades mais antigas exercidas pelo homem, data do período anterior ao Neolítico, os restos de cerâmica, cascas de ostras e mexilhões encontrados na Escandinávia, em período anterior ao Neolítico atestam a importância dos moluscos na alimentação humana (DIEGUES, 2003).

Assim como na agricultura, a natureza é o meio de trabalho dos pescadores artesanais que, para extrair dela as condições objetivas de sua reprodução social, desenvolveram e seguem desenvolvendo os mais variados sistemas técnicos de captura das diferentes espécies de pescado (PASQUOTTO e MIGUEL, 2005).

Para efeito conceitual a pesca artesanal pode ser definida como aquela em que o pescador sozinho ou em parcerias, participa diretamente da captura de pescado, utilizando instrumentos relativamente simples. Os pescadores artesanais retiram da pesca sua principal fonte de renda, ainda que, sazonalmente, possam exercer atividades complementares (DIEGUES, 1988).

O referido autor em sua publicação Pescadores, Camponeses e Trabalhadores do Mar (1983), traz exemplos de realidades que demonstram a íntima ligação entre a pesca artesanal e agricultura praticadas em regiões da Noruega, Suécia, Inglaterra, Holanda e Portugal no inicio do século XIX, além de estudos realizados em regiões litorâneas do Brasil, como São Paulo, Rio Grande do Norte e Ceará na década de 1970, referenciando os sujeitos que realizam as duas atividades como pescadoreslavradores.

Nem sempre essas comunidades culturalmente distintas se dedicavam exclusivamente a pesca, exerciam também atividades complementares, tais como a pequena agricultura e o artesanato. No entanto, com a modernização do campo e do mar e a invasão do capitalismo nas relações sociais, estas realidades foram se distanciando (DIEGUES, 1983).

Tomando como referência a realidade investigada na comunidade Apiques, Assentamento Maceió, município de Itapipoca$\mathrm{CE}$, onde as famílias realizam não apenas a pesca do tipo artesanal, contemplando as características trazidas por Diegues (1988), mas também, atividades no âmbito da agricultura de modo familiar, compartilhou-se da compreensão de Lima citado por Borgonha 
(2008), a respeito das famílias que praticam pesca artesanal no litoral cearense:

\begin{abstract}
Muitas comunidades litorâneas cearenses que tem na pesca artesanal o principal meio de produção e relevância socioeconômica e cultural, ainda desenvolvem atividades complementares as quais contribuem à conformação de seu particular modo de vida, caracterizando-as pela exploração dos recursos naturais e pelas relações construídas na terra, no mar e na interface terra/mar (2002, p.37).
\end{abstract}

Deste modo, para compreender a pesca artesanal como uma atividade econômica, modo de vida, expressão cultural e importante produtora de alimentos, torna-se imprescindível reconhecer não somente suas múltiplas funções para a sociedade como também as formas as quais esta é integrada com outras atividades realizadas não apenas pelos demais membros da família, bem como pelos próprios pescadores nas comunidades pesqueiras.

É necessário, para tanto, categorias analíticas que possam contribuir para desvelar a dinâmica da pesca artesanal. Assim, a multifuncionalidade e a pluriatividade surgem como ferramentas teórico-analíticas das atividades realizadas no espaço rural para colaborar na compreensão da racionalidade das famílias rurais, a partir de suas atividades.

Carneiro e Maluf (2003) trazem que a noção de multifuncionalidade aplicada a pescadores-lavradores rompe com 0 enfoque setorial e amplia o campo das funções sociais atribuídas à agricultura e à pesca realizadas por esses sujeitos sociais. Deixam de ser entendidas apenas como produtoras de bens agrícolas, tornando-se responsáveis pela conservação dos recursos naturais (água, solos, biodiversidade e outros), do patrimônio natural (paisagens) e pela qualidade dos alimentos.

Segundo Schneider (2003), o fenômeno da pluriatividade se caracteriza pela combinação das múltiplas inserções ocupacionais das pessoas que pertencem a uma mesma família. A emergência da pluriatividade ocorre em situações em que os membros que compõem as famílias domiciliadas nos espaços rurais combinam a 
atividade agrícola com outras formas de ocupação em atividades não agrícolas.

As noções de pluriatividade e multifuncionalidade da agricultura têm sido frequentemente acionadas no debate sobre as transformações recentes no meio rural, seja nos países desenvolvidos, seja no Brasil, onde o recurso à atividade não agrícola está estruturalmente integrado às estratégias de reprodução de grande parte das famílias camponesas (CARNEIRO, 2002).

Porém, as pesquisas relacionadas com multifuncionalidade e pluriatividade trazem como unidade de observação apenas as famílias que praticam agricultura familiar. Nesta pesquisa pretendeuse ampliar estes olhares também para analisar as famílias que realizam a pesca artesanal, não só de forma isolada, mas também combinada com a agricultura familiar e trabalhos não agrícolas.

Neste sentido, este artigo traz como objetivos analisar a pesca artesanal desenvolvida na comunidade Apiques, Assentamento Maceió, Itapipoca-CE à luz da multifuncionalidade, bem como identificar as atividades no âmbito da pluriatividade realizada pelas famílias da comunidade pesquisada.

\section{MÉTODO}

A pesquisa foi realizada no Assentamento Maceió, criado em 1985, situado no município de Itapipoca há 186 km de Fortaleza, no Litoral Norte Cearense. É formado por doze comunidades. Na divisão territorial dos Territórios da Cidadania o município de Itapipoca está inserido no Território Vales do Curu e Aracatiaçu (BRASIL, 2011).

De acordo com os dados do Plano de Desenvolvimento do Assentamento (PDA) construído em 2000 elaborado pela Organização Não Governamental (ONG) denominada Centro de Estudos do Trabalho e de Assessoria ao Trabalhador (CETRA), a área do Assentamento Maceió é composta de 3 imóveis, possuindo uma área total de 5.844,7119 hectares. Desta, a área efetiva de preservação ambiental permanente, formado por dunas móveis é de 699,488 hectares, tendo como capacidade em termos de famílias assentadas o número de 354. 
A pesquisa limitou-se a comunidade Apiques, que conta no horizonte temporal da pesquisa ${ }^{6} \mathrm{com}$ um total de 117 famílias, sendo 36 assentadas e 81 agregadas $^{7}$ num total de 491 habitantes. $^{8}$

A principal atividade econômica da comunidade é a pesca, variando sua intensidade e recursos pescados ao longo dos meses do ano. Porém, é bastante forte a presença de outras atividades, principalmente a agricultura, além de trabalhos não agrícolas como artesanato e trabalho assalariado (CAJADO, 2010).

Para obtenção dos resultados apresentados neste artigo foi utilizada a metodologia Análise Diagnóstico de Sistemas Agrários (ADSA). Esta foi aplicada de modo a possibilitar o envolvimento da pesquisadora com os sujeitos da pesquisa num processo de pesquisa participante, desde a coleta dos dados à discussão dos resultados junto à comunidade, logo se valendo da técnica de pesquisa - observação participante.

Minayo (2011) comenta que a observação participante é definida como um processo pelo qual um pesquisador se coloca como observador de uma situação social, com a finalidade de realizar uma investigação científica. O observador, no caso, fica em relação direta com os seus interlocutores no espaço social da pesquisa e na medida do possível participando da vida social deles, no seu cenário cultural, com a finalidade de colher dados e compreender o contexto da pesquisa.

A ADSA é utilizada pela Organização das Nações Unidas para Alimentação e Agricultura (FAO) e Universidades latinoamericanas, sendo resultado das reflexões e resultados de pesquisas levadas a efeito no Departamento de Agricultura Comparada e Desenvolvimento Agrícola do Instituto Paris Agro Tech, em Paris-FR. Este método consiste basicamente na investigação e caracterização da agricultura de uma região ou microrregião, cuja finalidade é fornecer subsídios para a elaboração de linhas estratégicas de desenvolvimento em termos locais (DUFUMIER, 1996; GARCIA FILHO, 1999; SILVA NETO; BASSO, 2005).

\footnotetext{
${ }_{7}^{6}$ A pesquisa ocorreu de abril de 2011 a janeiro de 2013.

7 São famílias que apesar de morarem no Assentamento não são cadastradas junto ao INCRA, também são denominadas de famílias não assentadas. Geralmente são famílias constituídas pelos filhos (as) e netos (as) de assentados (as) que ao casarem, na maioria dos casos, com pessoas do mesmo Assentamento permanecem no local e constroem suas casas próximas as casas de seus parentes. No entanto, não são contemplados com qualquer programa ou benefício referente à Reforma Agrária.

${ }^{8}$ Dados disponibilizados por uma não assentada e confirmados pela agente de saúde local. Atualizados em novembro de 2011.
} 
Deste modo, essa metodologia intervém desde as fases de identificação e elaboração dos projetos, ajudando na formulação das intervenções adaptadas às realidades concretas sendo constituída das seguintes etapas: Leitura de Paisagem e Caminhada Transversal; Entrevistas Históricas; Tipificação dos Sistemas de Produção; Itinerário Técnico e Econômico; Elaboração do Diagnóstico e Projeto de Implantação dos Sistemas Produtivos identificados.

A cada nível de análise deve ser dado um enfoque sistêmico, para que se compreendam as relações entre as partes e entre os fatos ecológicos, técnicos, sociais e econômicos que explicam a realidade.

Os resultados apresentados neste artigo são referentes aos resultados das etapas metodológicas: Tipificação dos Sistemas de Produção e Itinerário Técnico.

Contudo, ampliou-se a percepção das etapas metodológicas para a análise da pesca artesanal, pois originalmente a ADSA vêm sendo utilizada apenas para investigações inerentes a atividades do âmbito agrícola, porém sua abordagem sistêmica possibilitou fazê-lo sem nenhum prejuízo a consistência do método.

A Tipologia dos Sistemas de Produção consistiu em identificar e classificar como os sistemas de cultivo, criação, transformação e extrativismo estão relacionados de modo a caracterizar cada tipo de sistema.

Já a caracterização dos sistemas de produção, através do Itinerário Técnico, possibilitou mostrar a combinação das atividades produtivas e diferenciar os subsistemas. Foram construídos os Fluxogramas de Fertilidade e Produto e os Calendários de Atividades realizadas nos sistemas de produção e as relações entre os diversos subsistemas e sistemas.

Para tanto, foram realizadas entrevistas semiestruturadas orientadas por um roteiro contendo as questões relativas aos sistemas de produção praticados pelas famílias da comunidade Apiques. Estas entrevistas aconteciam geralmente nos espaços onde são realizados os diversos tipos de produção, de modo a possibilitar a participação da pesquisadora nas atividades, como nos roçados ${ }^{9}$ colhendo feijão, nos quintais produtivos, na casa de farinha

\footnotetext{
${ }^{9}$ São os plantios em consorcio de milho, feijão e em alguns casos mandioca realizados pelas famílias da comunidade Apiques.
} 
participando de farinhada, projetos coletivos, na praia e até mesmo em alto mar durante a pescaria.

Além de ouvir, de observar os manejos e as práticas, estes momentos possibilitaram perceber as relações entre os sujeitos e destes com o espaço e a paisagem rural a partir da realização das atividades de agricultura e pesca.

Quanto à amostragem referente às entrevistas realizadas nesta etapa, pautou-se no que afirma Dufumier:

\begin{abstract}
Levando-se em conta que os sistemas de produção agrícola podem ser bastante complexos, torna-se difícil e custoso proceder à sua análise detalhada a partir de um número muito grande de unidades de produção. É por isto que se costumam fazer estudos de caso apoiados em amostras relativamente restritas. A partir de uma tipologia prévia estabelecida com base na análise geral da situação agrária, escolhemse os estabelecimentos cujos sistemas de produção serão estudados (2007 p.93-94).
\end{abstract}

A partir da primeira família entrevistada de cada tipo da tipologia previamente elaborada, solicitou-se que a família indicasse outra com realidade semelhante a sua. Deste modo, configurando o tipo de amostragem não probabilística denominado snowball mais conhecida como "bola de neve", onde os participantes iniciais indicam novos participantes.

Conforme traz Wha, citado por Baldin e Munhoz (2011):

Essa técnica é uma forma de amostragem não probabilística utilizada em pesquisas sociais onde os participantes iniciais de um estudo indicam novos participantes que por sua vez indicam novos participantes e assim sucessivamente, até que seja alcançado o objetivo proposto (o "ponto de saturação"). O "ponto de saturação" é atingido quando os novos entrevistados passam a repetir os conteúdos já obtidos em entrevistas anteriores, sem acrescentar novas 
informações relevantes à pesquisa (1994, p. 332).

As entrevistas voltadas a cada tipo de sistema de produção previamente elaborado se esgotavam quando se percebia as homogeneidades nas respostas dos entrevistados.

Ressalta-se que no processo de construção de uma Tipologia definida, algumas pré-tipologias foram elaboradas a partir dos elementos trazidos nas entrevistas.

\section{RESULTADOS E DISCUSSÃO}

\subsection{Tipificação de Sistemas de Produção: Ampliando o olhar sobre a pesca artesanal}

A Tipificação dos Sistemas de Produção iniciou-se pela identificação e diferenciação no que se refere ao acesso a recursos naturais, aos recursos financeiros, representados pelas rendas extras externas as atividades inerentes aos sistemas de produção e recursos humanos, como mão de obra complementar a unidade familiar de produção. Destes, o fator mão de obra foi preponderante para a diferenciação dos tipos de sistemas de produção identificados na comunidade Apiques.

Nesta perspectiva, foram identificados oito tipos de sistemas de produção (Figura 1), oriundos da combinação dos sistemas e subsistemas apresentados no quadro abaixo (Figura 2). 
Figura 1- Tipologia dos Sistemas de Produção identificados na comunidade Apiques, Assentamento Maceió, Itapipoca-CE.

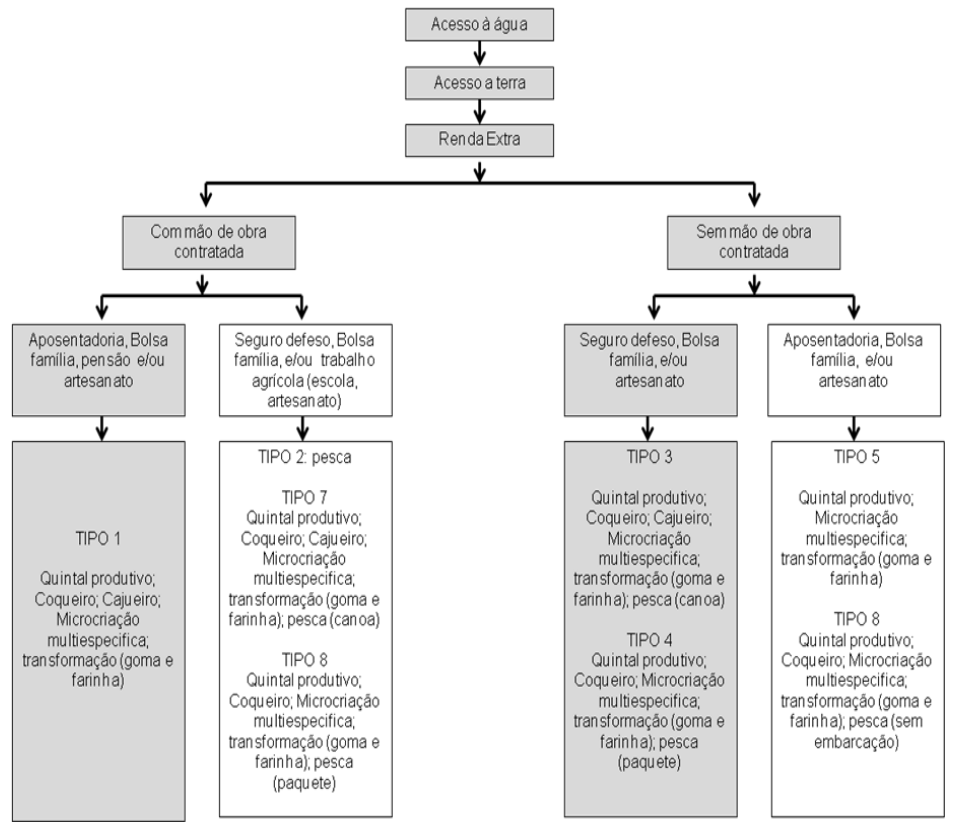

Fonte: Dados da pesquisa. (2011-2013).

Figura 2- Quadro dos sistemas e subsistemas de produção que formam os sete tipos de sistemas de produção identificados na comunidade Apiques, Assentamento Maceió, Itapipoca-CE.

\begin{tabular}{|c|c|}
\hline SISTEMAS DE PRODUÇÃO & SUBSISTEMAS DE PRODUÇÃO \\
\hline Cultivo & $\begin{array}{c}\text { Coqueiro, cajueiro, outras fruteiras, } \\
\text { feijão, milho, mandioca, batata doce, } \\
\text { horta. }\end{array}$ \\
\hline Criação & $\begin{array}{c}\text { Microcriação multiespecífico (apenas } \\
\text { aves), galinhas, patos, perus, } \\
\text { capotes, gansos. }\end{array}$ \\
\hline Transformação & Mandioca (farinha, goma, borra) \\
\hline Extrativismo & Pesca (canoa e paquete) \\
\hline
\end{tabular}

Fonte: Dados da pesquisa, (2011-2013). 
Apesar da diferenciação entre os sistemas de produção ser o fator mão de obra, isto não se concebe em forma de contrato propriamente, pois as atividades relacionadas à agricultura familiar normalmente são realizadas pela família, compreendendo não apenas marido, esposa e filhos (as), mas também, irmãos (as), cunhados (as), tios (as), enfim numa leitura da dinâmica da agricultura familiar baseada nas relações de parentesco, na reciprocidade, onde de forma esporádica, paga-se uma a duas diárias por ano.

Para Firth (1974) em pequenas comunidades as pessoas possuem sistemas de troca internos elaborados, que preenchem mais as finalidades sociais do que as diretamente econômicas.

Já no caso da pesca, quando os pescadores não possuem nenhuma relação de parentesco direta, o pescador dono da embarcação recebe um percentual da produção dos outros pescadores, uma espécie de sistemas de partes, denominada "trêsum"

Porém, este lógica não é contratual, pois se os pescadores considerarem a produção pequena, eles priorizam consumo familiar, onde cada um leva para casa sua produção ou parte dela, já que os laços de solidariedade são muito fortes entre as famílias da comunidade, onde geralmente os pescadores que por algum motivo encontram-se impossibilitados de irem pescar recebem dos demais parte da produção para garantir seu alimento.

Logo em relação à mão de obra, mesmo quando há a necessidade de contratar, ela ocorre de forma complementar à força de trabalho da família (CHAYANOV, 1974). Para Carneiro e Maluf (2005) ao privilegiar a família em suas complexas relações com a sociedade, à noção da multifuncionalidade incorpora à análise certos fenômenos que se inscrevem em diferentes domínios do universo social, e que normalmente não são levados pelas análises econômicas dominantes.

Observa-se que todos os tipos de sistemas de produção possuem alguma renda extra, seja oriunda de trabalhos não agrícolas, como artesanato, comércio, serviço público, seja de transferências sociais como Bolsa Família e/ou recursos

\footnotetext{
${ }^{10}$ É uma forma de divisão da produção onde o pescador dono da embarcação recebe a cada $3 \mathrm{~kg}$ de peixe vendido o valor de $1 \mathrm{~kg}$. No entanto este sistema não é utilizado em todos os tipos de pescarias.
} 
previdenciários como aposentadoria e Seguro Defeso ${ }^{11}$, mostrando a importância destas rendas para as famílias no meio rural que, apesar de desenvolverem sistemas de produção diversificados, geralmente são destinados para o autoconsumo.

Deste modo, as rendas não agrícolas contribuem para a permanência das famílias em seu lugar de origem, refletindo além da diminuição do êxodo rural, ampliação da percepção do rural como espaço de vida. Essa afirmativa se verifica na fala de um jovem pescador-agricultor de 25 anos da comunidade, beneficiado pelo Seguro Defeso da lagosta "[...] Eu não sei o que fazer longe daqui, distante do mar, apesar de não ter emprego, eu gosto daqui [...]".

De acordo com Carneiro e Maluf (2005) o caráter multifuncional da agricultura familiar destaca sua importância na manutenção da população rural através da produção para autoconsumo que, associada à pluriatividade, permite a reprodução social das famílias com condições de produção limitadas e, consequentemente, com renda de origem agrícola fraca se comparadas aos níveis de mercado. Estas afirmativas também podem ser aplicadas na compreensão da lógica da pesca artesanal que exprime seu caráter multifuncional no processo de reprodução social das famílias da comunidade pesquisada.

A Tipologia mostra os diversos sistemas de produção realizados pelas famílias, mas não se torna suficiente para observar qual a dinâmica destes e se há dependências externas como insumos, capital financeiro ou até mesmo capital humano (CAJADO et al, 2011).

Para compreender como a pesca artesanal é realizada em combinação com outras atividades, verificar as relações de sinergia e dependência com variáveis externas, bem como a importância das rendas extras aos sistemas foram construídos Fluxogramas de Fertilidade e Produtos e Calendários de Atividades do tipo 2 que possui apenas como sistema de produção a pesca e do tipo 3 que se que apresenta bastante diversificado, sendo observado a pesca como sistema de extrativismo.

\footnotetext{
11 Benefício social destinado de dezembro a março aos pescadores de lagosta devidamente licenciados para este tipo de pesca no período de reprodução das espécies Panulirus Argus e Panulirus Laevecauda, conhecidas respectivamente como Lagosta Vermelha e Lagosta Verde.
} 


\subsection{Fluxogramas de Fertilidade e Produto e Calendários de Atividades}

Figura 3- Fluxo de Fertilidade e Produto do sistema de produção tipo 2.

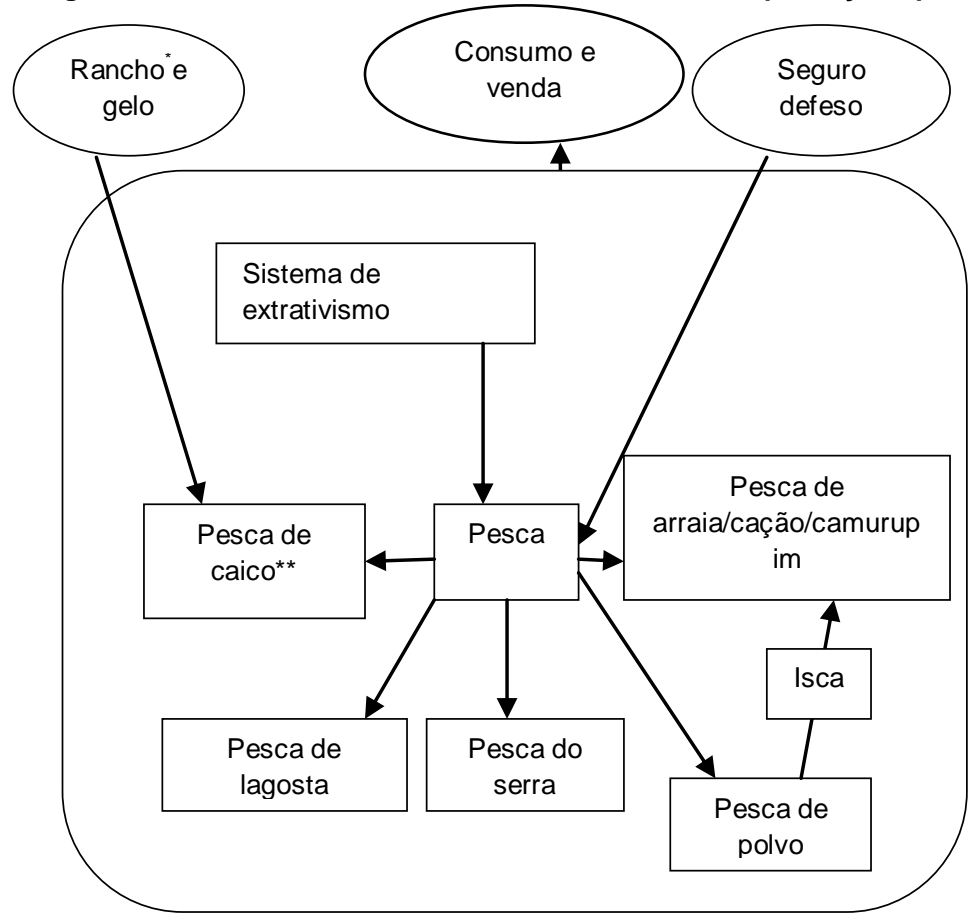

Fonte: Dados da pesquisa (2011-2013).

O sistema de produção tipo 2 foi dividido em A e B (Figuras 4 e 5) devido haver algumas diferenças quanto aos subsistemas que compõem o sistema de extrativismo pesca, porém ambos são realizados por famílias que contam com fontes de renda externas ao sistema.

Apesar de ser observada a presença de rendas extras em todos os sistemas de produção, o Fluxograma revela que estas não têm relação direta com a sustentabilidade do sistema, exceto 0 
Seguro Defeso quando parte é utilizado para manutenção da embarcação e instrumentos de pesca.

No entanto por se tratar de um sistema de produção pouco diversificado se comparado com os demais, além da pesca ser uma atividade economicamente instável, as rendas extras apresentam-se como uma fonte de renda estável para a reprodução familiar.

*Refere-se ao alimento que os pescadores levam para pescaria de duração superior a meio dia (12 horas). Também é conhecida por quimanga.

** Trata-se da pesca do peixe com menor valor comercial de espécies variadas. Porém, por ser realizada com linha de mão, podem também neste tipo de pescaria, ser capturados peixes de valor comercial mais significativo, como o Sirigado (Mycteroperca bonassi) e a Garoupa (Epinephelus marginatus).

Figura 4- Calendário de atividades do sistema de produção $2 \mathrm{~A}$.

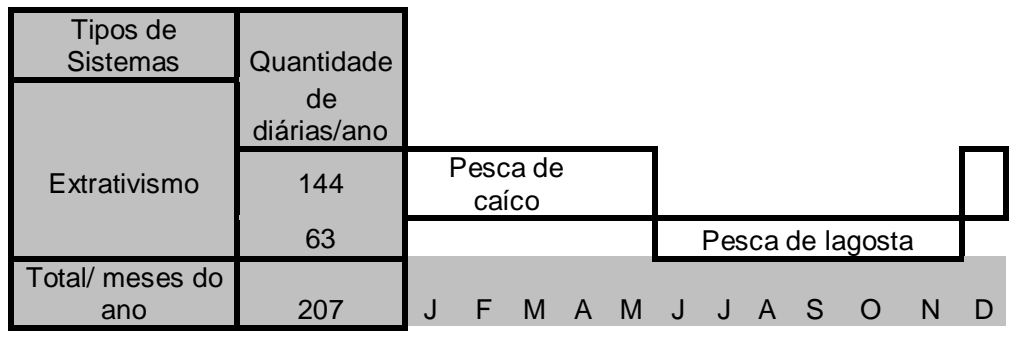

Fonte: Dados da pesquisa (2011-2013).

Figura 5-Calendário de atividades do sistema de produção 2B.

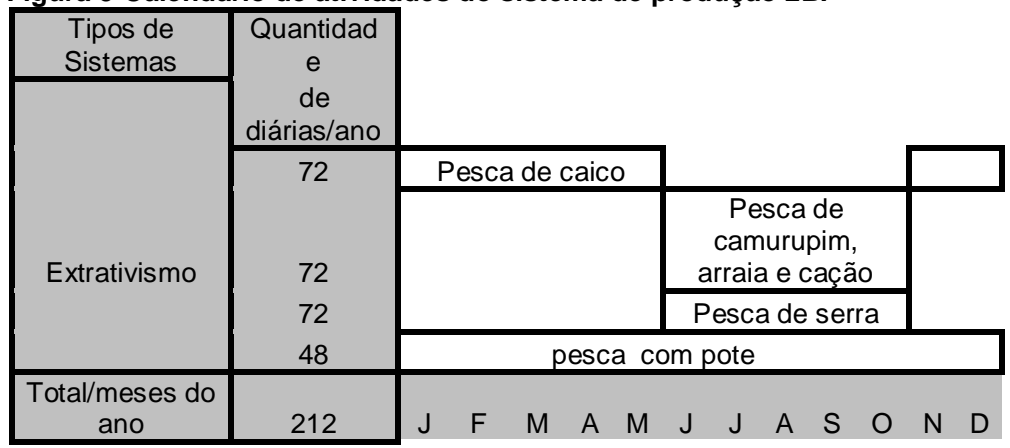

Fonte: Dados da pesquisa (2011-2013). 
A multifuncionalidade contribui para a compreensão da pesca artesanal não apenas por sua relevância produtiva, o que é incontestável, mas possibilita visibilizar sua importância enquanto categoria, compositora de uma identidade social, conhecedora de saberes adquiridos a partir da convivência com a natureza e repassados por gerações, conservadora de laços sociais e simbólicos e de parte de uma cultura pertencente a toda à sociedade.

Estes elementos são percebidos a partir da fala de um pescador- agricultor de 29 anos da comunidade pesquisada quanto questionado com quem aprendeu a pescar e se tem orgulho de ser pescador: "[...] Aqui as pessoas ensinam uns as outras. Eu não tenho vontade de sair da pesca, tudo que eu trabalho, aqui é meu e da minha família. Chego do mar, dô peixe a um amigo. [...]".

Segundo Carneiro e Maluf (2005), o olhar através da lente da multifuncionalidade torna visível à contribuição não diretamente produtiva desta população para a dinâmica econômica, social e cultural da sociedade, justificando assim a remuneração, sob diversas formas, de serviços prestados e consumidos pela sociedade como se fosse um bem "natural". 
Figura 6- Fluxo de Fertilidade e Produtos do Sistema de Produção tipo 3.

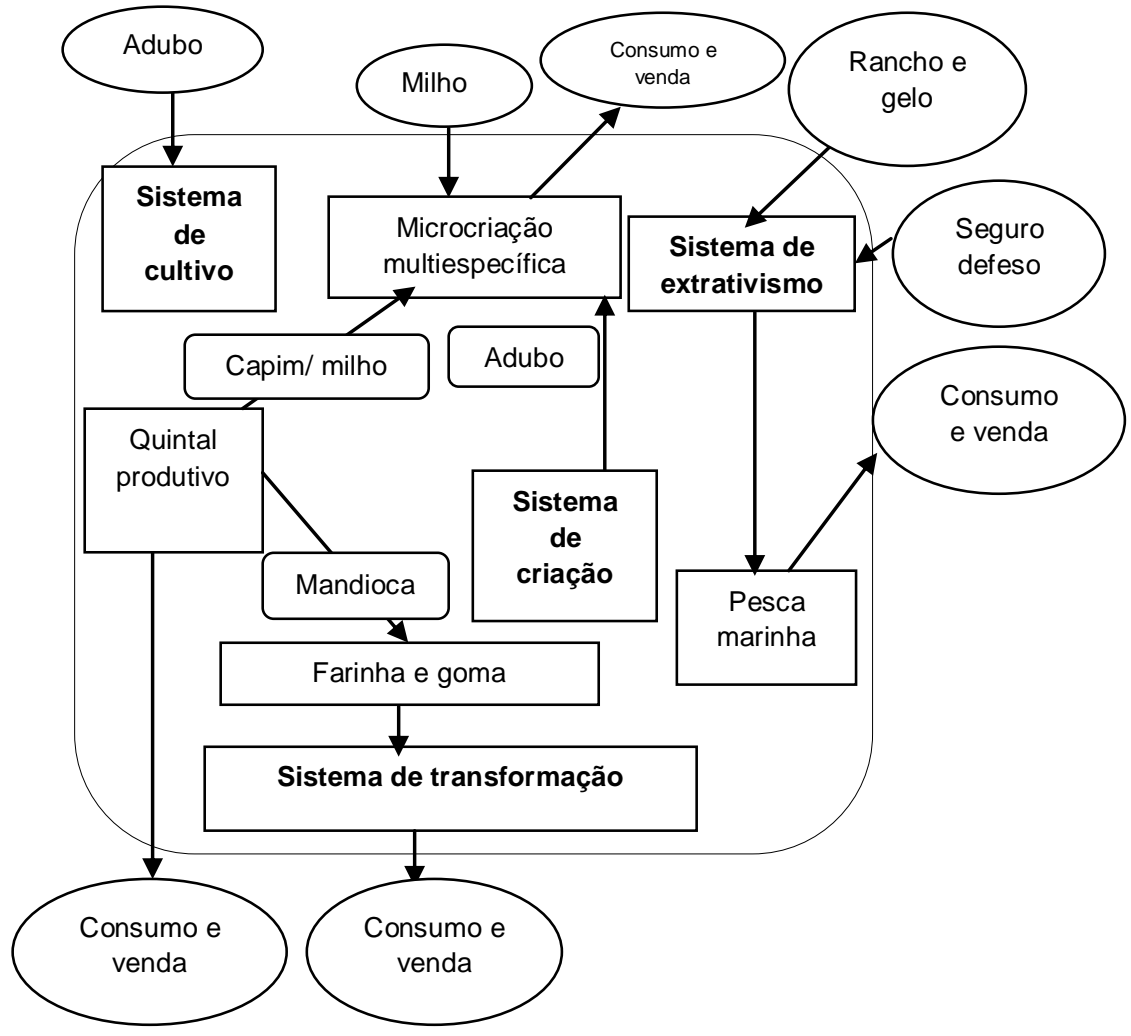

Fonte: Dados da pesquisa (2011-2013).

Através do Fluxograma são observadas poucas entradas de energia no sistema, caracterizando reduzida dependência de insumos externos, logo com tendência a sustentabilidade, além dos produtos que são gerados, onde tem como principal destino o consumo por parte das famílias, contribuindo com a segurança alimentar, dando ao espaço rural uma função predominantemente de reprodução familiar.

Apresenta ainda as diversas atividades que as famílias desenvolvem ao longo do ano, bem como as relações de sinergia entre os sistemas de produção, onde os subsistemas realizados nos 
sistemas de cultivo e criação são praticados geralmente no mesmo espaço próximo as casas, nos quintais produtivos, cuja área varia de 0,5 até 6 hectares. Neste processo, cabe à família e a seus membros um papel ativo, pois suas decisões, estratégias e ações podem trazer resultados benéficos ou desfavoráveis à continuidade e à reprodução (SCHNEIDER, 2003).

Assim como o sistema de produção tipo 2, as rendas extras não estão diretamente relacionadas com o desenvolvimento das atividades agrícolas familiares, exceto o Seguro Defeso da lagosta, conferindo assim um grau de autonomia das famílias na realização destas atividades em relação as transferências sociais. Ressalta-se que, dentre as rendas extras ao sistema de produção tipo 3, não são verificados trabalhos não agrícolas.

Este fato pode estar relacionado com a mão de obra disponível e o nível de diversidade do sistema, já que este não conta com contribuição de mão de obra externa à família. No entanto possui um alto grau de diversificação de suas atividades, sendo refletido inclusive na quantidade de diárias prestadas pelas famílias que desenvolvem este tipo de sistema de produção.

Chayanov (1974) explica este tipo de comportamento das famílias camponesas em sua teoria denominada "diferenciação demográfica", onde faz a relação da capacidade de trabalho familiar com o ciclo de vida familiar, cuja lógica da produção está diretamente relacionada com a satisfação das necessidades de seus membros.

Desta forma, ao passo que os filhos (as) vão crescendo em idade e vão consumindo mais, também vão se tornando mão de obra numa relação consumo/trabalho.

Contudo, apesar da diminuição dos riscos por meio da diversificação das atividades, a pluriatividade representa uma alternatividade para complementar a renda agrícola, principalmente em casos onde a mão de obra disponível é superior a quantidade de força de trabalho necessária para as atividades agrícolas familiares no sistema. Conforme afirma Schneider (2003):

Em situações em que a família não dispõe de uma quantidade suficiente de terra para suas necessidades, ou quando sobram braços para trabalhar, ela tende a buscar em atividades artesanais e comerciais ou em outras atividades não agrícolas uma forma de 
ocupar a força de trabalho para garantir o equilíbrio entre trabalho e consumo (2003 p. 107).

Quando Carneiro (2002) traz que tanto a noção de pluriatividade quanto a de multifuncionalidade recuperam uma característica da agricultura camponesa: a agricultura como modo de vida (integrada ao conjunto da sociedade e ancorada em um território) e não como uma profissão como qualquer outra, percebese que essa análise se faz interessante também na compreensão da pesca artesanal, pois, assim como a agricultura camponesa, a pesca artesanal guarda elementos de um modo de vida relacionado com a natureza, com a paisagem rural, bem como um papel de produtora de alimentos para a sociedade. Logo é importante ampliar o olhar sobre o espaço rural a partir das pluralidades dos sujeitos que 0 compõem.

Para a nossa discussão fora do campo europeu, convém ampliar o sentido do termo camponês, a fim de abarcar outros tipos de pequenos produtores tais como o pescador ou o artesão rural, que participam do mesmo tipo de organização econômica simples e vida em comunidade. Pode-se argumentar que existe quase tanta diferença entre os sistemas econômicos pastoris e de cultivo europeus, quanto entre um cultivador oriental e seu irmão pescador, que pode de fato ser também um agricultor camponês parte do tempo (FIRTH, 1974, p. 102). 
Figura 7- Calendário de atividades do sistema de produção 3.

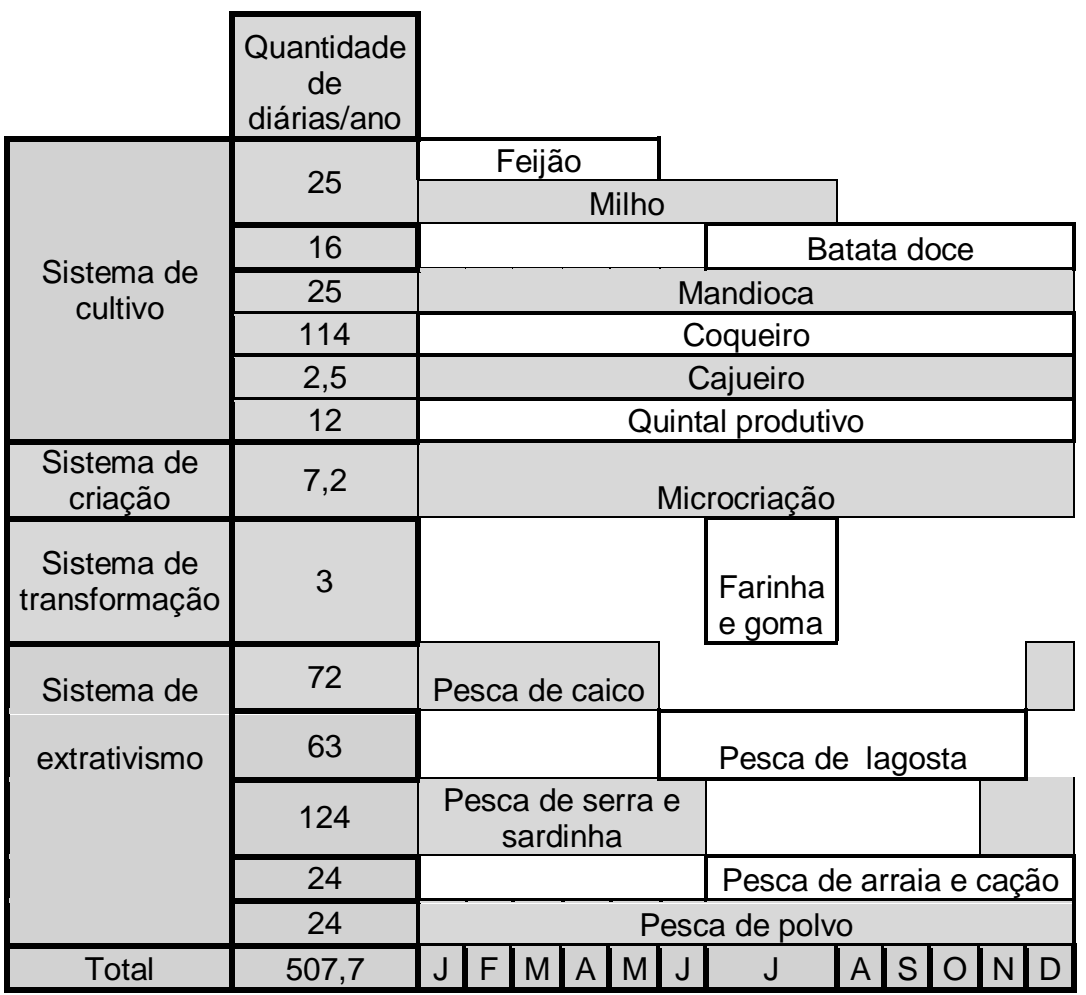

Fonte: Dados da pesquisa (2011-2013).

O calendário do sistema de produção tipo 3 reafirma a capacidade que a unidade de produção familiar possui de diversificar suas atividades, tendo em vista o mão de obra e por sua vez, a satisfação das necessidades internas de seus membros, refletidos no potencial em diárias trabalhadas ao longo do ano.

A diversidade de subsistemas e suas relações intrínsecas revelam ainda a capacidade que as famílias possuem de internalizar as atividades no espaço agrícola, otimizando a unidade de produção familiar (CAJADO et al., 2011). 
Estes resultados sugerem a complexa relação das famílias com os recursos naturais e o espaço rural no processo de composição e transformação deste espaço em território construído e reafirma a caráter multifuncional que advém das atividades agrícolas familiares, ampliando seu papel na sociedade na construção da sustentabilidade. De acordo com Diegues (2000):

\begin{abstract}
Essa representação simbólica do cíclico, de que tudo no cosmo nasce, morre, renasce é forte nas sociedades primitivas, mas está presente também nas comunidades tradicionais de pequenos agricultores itinerantes, de pescadores e coletores que ainda vivem ao sabor dos ciclos naturais e num complexo calendário agrícola ou pesqueiro. Há o tempo para fazer a coivara, preparar a terra, semear, capinar e colher, como também há o tempo de se esperar as espécies de peixes migratórios, como a tainha. Uma vez terminado esse ciclo, ele recomeçará no período seguinte. Em muitas dessas comunidades, essas atividades são comandadas por sinais, como o aparecimento de uma lua determinada, da chuva etc. Esses "tempos" são muitas vezes celebrados por festividades que marcam o início ou o fim de determinada safra, a colheita, por exemplo, (2000, p. 34).
\end{abstract}

Sinais destas complexas relações podem ser percebidos na fala de agricultora-marisqueira e artesã de 51 anos: "[...] Aqui é tudo misturado, é a agricultura e o mar, não tem nada dividido não [...]".

\title{
4. CONSIDERAÇÕES FINAIS
}

A multifuncionalidade permite analisar a pesca artesanal sob aspectos que superam a lógica produtivista, visibilizando sua importância enquanto modo de vida, por centralizar a família e suas relações com o espaço rural e a natureza, além de reconhecer sua relevância para a sociedade através dos diversos serviços materiais e simbólicos prestados como a produção de alimento de alta qualidade, permanência da cultura e histórias relacionadas com 0 
mar, manutenção do tecido social da categoria enquanto pescadores (as) artesanais, além de compor a paisagem rural e costeira.

Contudo, é necessário o reconhecimento destas externalidades positivas oriundas da pesca artesanal pelo Estado, através de políticas públicas que valorizem e fomentem as diversas funções prestadas à sociedade por esta categoria social, até mesmo como forma de amenizar as tensões que estes povos sofrem muitas vezes por habitarem em territórios de interesse da especulação imobiliária e do turismo exploratório.

As rendas extras, apesar de não estarem diretamente relacionadas com a manutenção dos sistemas de produção, são essenciais para a reprodução familiar.

No entanto, a obtenção de renda extra através de trabalhos não agrícolas não aparece externa a todos os tipos de sistemas de produção. Logo mostra-se importante ampliar as oportunidades de emprego no campo no âmbito da pluriatividade, porém compreendendo a pluriatividade como serviços não agrícolas que possam ao mesmo tempo gerar emprego, renda e melhorar a qualidade de vida da comunidade rural, com a capacitação e contratação de recursos humanos locais para trabalharem nas escolas, postos de saúde e demais estabelecimentos e serviços que contribuam para o desenvolvimento do espaço rural.

São necessárias políticas públicas capazes de assistir a diversidade do espaço rural na ótica da pluriatividade e multifuncionalidade de modo a incluir em suas ações os processos que já estão em construção pelas famílias, estimulando a participação dos sujeitos sociais nas tomadas de decisões.

\section{REFERÊNCIAS BIBLIOGRÁFICAS}

BRASIL, Ministério do Desenvolvimento Agrário. Plano Territorial de Desenvolvimento Rural Sustentável: Território Vales do Curu Aracatiaçu - MDA/SDT/Fortaleza: Instituto Agropolos do Ceará, 2011, 422 p.

CAJADO, Diana. M. Multifuncionalidade, pluriatividade e pesca artesanal: um estudo de caso da comunidade Apiques, Assentamento Maceió - Itapipoca-CE. UFC, 2010. Monografia em Engenharia de Pesca. Fortaleza, 2010, 58 p.

CAJADO, Diana. M. et al. Multifuncionalidade e pluriatividade como alternativas para o desenvolvimento rural sustentável: $O$ caso da 
comunidade Apiques, Assentamento Maceió-Itapipoca-CE. In: III Fórum Brasileiro do Semiárido, 3, Sobral-CE, 2011. Anais...Sobral-CE.

CARNEIRO, Maria. J.: Multifuncionalidade da agricultura e ruralidades: uma abordagem comparativa. In: MOREIRA, R. J; COSTA, F. de C. (org.) Mundo rural e cultura. Rio de Janeiro: Mauad, 2002, $313 \mathrm{p}$.

CARNEIRO Maria. J. Maluf Renato. S. (Eds). Para além da produção: multifuncionalidade e pluriatividade da agricultura. Rio de Janeiro: Mauad /Nead, 2003, 230 p.

. : Multifuncionalidade da

agricultura familiar. In: BOTELHO FILHO, F. B (org.) Agricultura familiar e desenvolvimento territorial: contribuições ao dabate. Brasília: UNB, v. 5, n.17, 2005168 p.

CHAYANOV, Alexander. V. La organizacíon de La unidad economica campesina. Buenos Aires: Nueva Vision, 1974, 342p.

DIEGUES, Antônio. C. Pescadores, Camponeses e Trabalhadores do Mar. 1. ed. São Paulo: Ática, 1983, 294 p.

Paulo: HUCITC, 2000, 102 p.

O mito da natureza intocada. 3. ed. São A interdisciplinaridade nos estudos do

mar: $O$ papel das ciências sociais. Conferência proferida na XV Semana de Oceanografia, Instituto Oceanográfico da USP, Outubro, 2003. Disponível em <http://www.usp.br/nupaub/interdis.pdf >Acesso: em 15 mai. De 2012.

DUFUMIER, Marc. Projetos de desenvolvimento agrícola: manual para especialistas. Salvador: EDUFBA, 2007, 326 p.

FIRTH, Raymond, W. Elementos da organização social. Tradução: Dora Flaksman e Sérgio Flaksman. Rio de Janeiro: Zahar, 1974, 274p.

GARCIA FILHO, Danilo P. Guia metodológico de diagnóstico de sistemas agrários. Brasília: INCRA/FAO, 1999, 65p.

MINAYO, Cecília, de S. Trabalho de campo: contexto de observação, interação e descoberta. In: MINAYO, C.de.S (org.) Pesquisa social. 30 ed. Rio de Janeiro: Vozes, 2011, p.61-77. 
PASQUOTTO, Vinicius. F; MIGUEL, L. de A. Pesca artesanal e enfoque sistêmico: uma atualização necessária. In: Agricultura familiar e abordagem sistêmica. 1ed. Aracaju: Sociedade Brasileira de Sistemas de Produção, 2005, p. 61-80.

RAMIRES, Milena; BARELLA, Walter; CLAUZET, Mariana. A pesca artesanal no Vale do Ribeira e litoral sul do Estado de São Paulo - Brasil. Disponível em: <http://www.anppas.org.br/encontro_anual/encontro1/gt/biodiversida de/Milena\%20R mies.pdf.> Acesso: em 03 mai. de 2011.

SCHNEIDER, Sérgio. Teoria social, agricultura familiar e pluriatividade. São Paulo: Revista Brasileira de Ciências Sociais, v. 18 , n. 51 , p. $99-123$, fev. 2003. 